although a transesophageal echocardiogram with agitated saline contrast was not performed to completely rule out a patent foramen ovale with an intermittent right to left shunt.

It was assumed that this aneurysm was related to a sump drain placed at the time of surgery. This would have been common practice in the surgical era during which the patient's ventricular septal defect was repaired. Unfortunately, the hospital where the patient underwent surgery no longer exists, and operative notes were not available for review. It is possible that the LV aneurysm was congenital, because a significant proportion $(26 \%)$ of congenital LV aneurysms reported in the literature have been associated with ventricular septal defect. ${ }^{5}$ However, in this patient, the size and location of the defect were most consistent with an LV sump aneurysm.

\section{CONCLUSIONS}

This case supports consideration of a sump aneurysm as a potential source of thromboembolism in a patient with prior surgical correction of a congenital heart defect.

\section{References}

1. Weesner KM, Byrum C, Rosenthal A. Left ventricular aneurysms associated with intraoperative venting of the cardiac apex in children. Am Heart J. 1981;101: 622-5.

2. Ohlow MA, Secknus MA, Geller JC, von Korn H, Lauer B. Prevalence and outcome of congenital left ventricular aneurysms and diverticula in an adult population. Cardiology. 2009;112:287-93.

3. Haegeli LM, Ercin E, Wolber T, Brunckhorst C, Tanner FC, Jenni R, et al. Arrhythmic manifestations in patients with congenital left ventricular aneurysms and diverticula. Am J Cardiol. 2011;108:1826-30

4. Weesner KM, Byrum CJ, Dick M, Rocchini AP, Behrendt DM, Hees P. Ventricula tachycardia associated with a left ventricular apex sump aneurysm in an adolescent. Am Heart J. 1983;105:334-6.

5. Ohlow MA. Congenital left ventricular aneurysms and diverticula: definition, pathophysiology, clinical relevance and treatment. Cardiology. 2006;106: 63-72.

\title{
Delayed presentation of aortic laceration from seventh rib fracture: An uncommon complication
}

\author{
Riley Kitamura, BA, ${ }^{a}$ Modesto Colon, MD, ${ }^{a}$ and Jasmine Dave, MD, ${ }^{\mathrm{b}}$ New York, NY
}

Rib fractures are common in blunt trauma and markers of the severity and multisystem scope of the injury. Traumatic aortic injury is a leading cause of mortality, with the majority of cases involving violent deceleration injuries that result in aortic rupture and immediate death; only $15 \%$ of patients with blunt aortic injury arrive at the hospital alive. ${ }^{1,2}$ Traumatic injury to the aorta by a fractured rib is rare yet also threatens the life of the patient. We report a patient with descending aortic laceration from a traumatic rib fracture who presented 2 days after the initial trauma.

\section{CLINICAL SUMMARY}

A 63-year-old man was admitted after a 30-foot fall. A computed tomography (CT) scan demonstrated a left

\footnotetext{
From the Mt Sinai School of Medicine, ${ }^{\mathrm{a}}$ New York, NY; and Division of General Surgery, ${ }^{b}$ Department of Surgery, Mt Sinai School of Medicine, Elmhurst Hospital Center, New York, NY

Disclosures: Authors have nothing to disclose with regard to commercial support.

Received for publication June 6, 2012; revisions received Aug 1, 2012; accepted for publication Aug 14, 2012; available ahead of print Sept 10, 2012.

Address for reprints: Jasmine Dave, MD, Division of General Surgery, Elmhurst Memorial Hospital, 79-01 Broadway, Elmhurst, NY 11373 (E-mail: davej@ nychhc.org).

J Thorac Cardiovasc Surg 2012;144:e121-3

0022-5223/\$36.00

Copyright (c) 2012 by The American Association for Thoracic Surgery

http://dx.doi.org/10.1016/j.jtcvs.2012.08.036
}

hemothorax and pneumothorax and left flail chest with posterior-medial fractures of ribs 5 to 11 . The fractured posterior tip of the seventh rib was angled anteriorly resting approximately $5 \mathrm{~mm}$ from an unremarkable descending aorta in CT 3-dimensional reconstructions (Figure 1). There was no extravasation of contrast on the CT scan. Additional injuries were transverse process fractures of thoracic vertebrae 10 and 12 and lumbar vertebrae 1 to 5 , spinous process fracture of lumbar vertebrae 1 to 3 , and left renal parenchyma contusion.

The patient underwent insertion of an intercostal chest drain with $500 \mathrm{~mL}$ of sanguineous output. A subsequent chest roentogram was negative for residual hemothorax. The patient remained stable until the morning of hospital day 2. At that time, a sudden output of 2.5 liters of blood from the chest drain was noted. The patient was immediately taken to the operating room. Because the CT scan demonstrated an uninjured aorta, initial exploration began with video-assisted thoracoscopy. Exploration evacuated 1.5 liters of blood and noted the posterior fractured tip of the seventh rib abutting a small clot covering the aortic adventitia. A left posterolateral thoracotomy was performed, and a 4-mm puncture wound in the descending aorta adjacent to the seventh rib was noted. There was no evidence of aortic dissection or intramural hematoma, and the aorta 


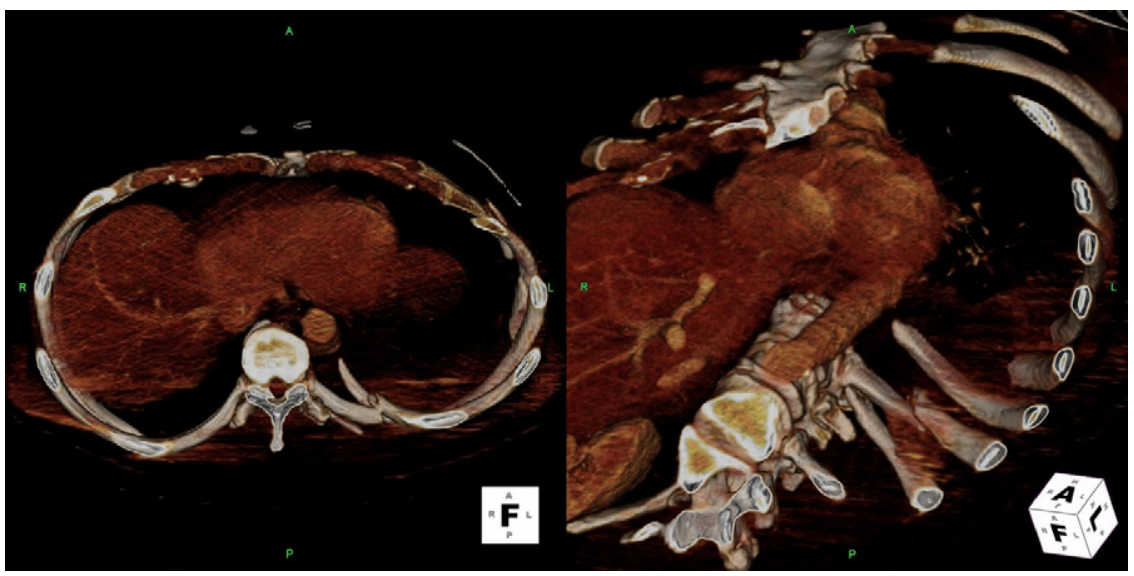

FIGURE 1. Inferior transverse (left) and inferior oblique (right) views. Note the posterior-medial fractured tip of rib 7 resting less than $5 \mathrm{~mm}$ from the thoracic aorta.

was repaired with a pledgeted suture of 3-0 Prolene. The fractured rib was resected. The patient was discharged 2 weeks later.

\section{DISCUSSION}

Thoracic trauma represents $10 \%$ to $15 \%$ of all trauma and $25 \%$ of trauma-related deaths. The majority of cases involve rib fractures, which are associated with the development of hemothoraces and pneumothoraces. Fracture of the upper ribs increases the risk for great vessel injury, and fracture of the lower ribs is associated with injury to the kidneys, liver, or spleen. ${ }^{1}$

Fracture of the lower ribs resulting in aortic injury is an uncommon complication, and there are only 4 other cases reported in the English literature, all involving left rib fractures. In all the cases, puncture of the aorta by the fractured rib manifests clinically with sudden life-threatening hemorrhage and clinical instability that can occur 3 to 15 days after the inciting trauma. ${ }^{3-5}$ As noted in our patient, initial chest roentogram and $\mathrm{CT}$ imaging often fail to demonstrate aortic injury.

Two of the reports noted that the injury manifested after the patient had been moved or after physiotherapy. The reason for the delayed manifestation is unclear in all these cases. Perhaps the aortic injury was immediate but sealed because of the small size of the laceration, and bleeding occurred when the clot was dislodged, or perhaps the injury occurred when the patient was moved.

Given the unpredictable and life-threatening nature of aortic injury induced by anteriorly displaced fractures of the lower posterior ribs and the variable time period before the injury manifests itself, prophylactic rib resection can be considered in cases with significant potential for aortic injury. Our group recently encountered another case of a left posterior fifth rib fracture; CT showed

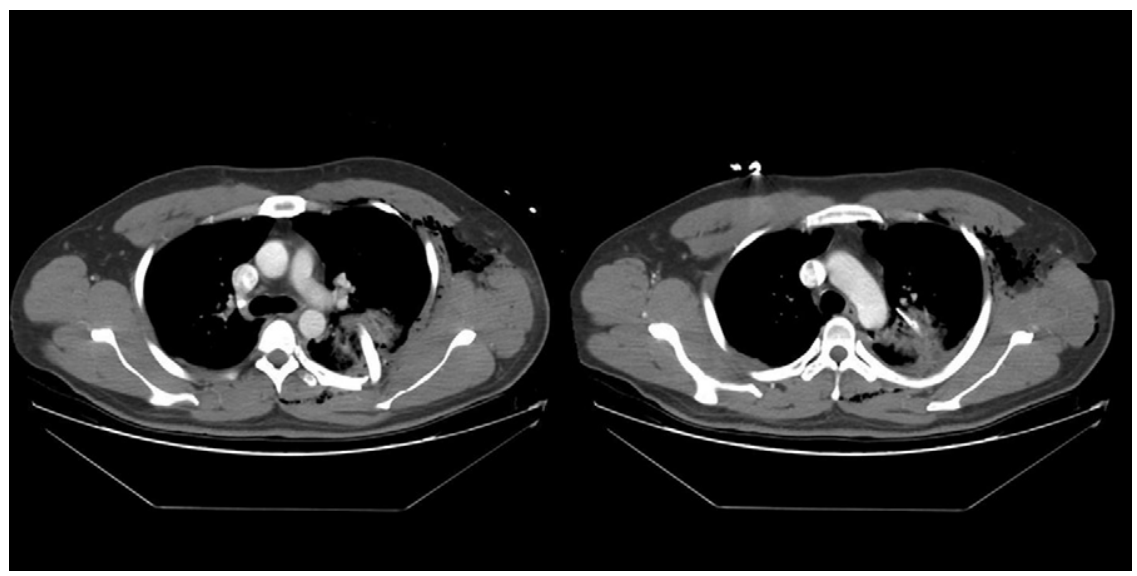

FIGURE 2. CT thorax axial view of a left posterior fifth rib fracture right below the level of the aortic arch (left) and at the level of the arch (right). Note the fractured rib has been anteriorly displaced within $7 \mathrm{~mm}$ of the aorta. 
the rib to be anteriorly displaced and within $7 \mathrm{~mm}$ of the descending aorta (Figure 2). We elected to remove the rib fragment, and the patient was discharged within 1 week. Sata and colleagues ${ }^{6}$ also reported successful resection of a rib fragment seen to be migrating toward the thoracic aorta over serial CT scans. Sata and colleagues elected to perform open thoracotomy for rib resection, as in our case; however, a video-assisted thoracoscopic approach also may be a viable option in less complicated cases.

\section{CONCLUSIONS}

Although rib fracture-induced injury of the aorta is rare, given the severe implications of aortic injury, we recommend consideration of prophylactic resection of the rib fragments that threaten the aorta. Imaging studies such as
CT and 3-dimensional reconstructions may assist physicians in developing their threshold for prophylactic surgery in the future.

\section{References}

1. Sirmali M, Turut H, Topcu S, Gulhan E, Yazici U, Kaya S, et al. A comprehensive analysis of traumatic rib fractures: morbidity, mortality and management. Eur J Cardiothorac Surg. 2003;24:133-8.

2. Bruno V, Batchelor T. Late aortic injury: a rare complication of a posterior rib fracture. Ann Thorac Surg. 2009;87:301-3.

3. Marco J, Gregory J. Posterior fracture of the left sixth rib causing late aortic laceration: case report. J Trauma. 1997;42:736-7.

4. Akira I, Satoh N, Yamakawa H, Fujino M, Hiroshima K, Fujisawa T. Rupture of the descending thoracic aorta caused by blunt chest trauma: report of a case. Surg Today. 2003;33:755-7.

5. Ashrafian H, Kumar P, Sarkar P, DeSouza A. Delayed penetrating intrathoracic injury from multiple rib fractures. J Trauma. 2003;58:858-9.

6. Sata S, Yoshida J, Nishida T, Ueno Y. Sharp rib fragment threatening to lacerate the aorta in a patient with flail chest. Gen Thorac Cardiovasc Surg. 2007;55: $252-4$

\title{
Cardiac transapical approach: A new solution for the treatment of complex thoracic aortic disease
}

\author{
Bruno Borrello, MD, Francesco Nicolini, MD, PhD, Andrea Agostinelli, MD, PhD, and \\ Tiziano Gherli, MD, Parma, Italy
}

Endovascular repair of descending thoracic aorta pathology has become a well-recognized therapeutic option, ${ }^{1}$ although several patient results are unsuitable anatomically for standard treatment with current devices. ${ }^{2}$ Severe vascular occlusive disease may not allow the insertion of these large devices through the iliofemoral vessels or the abdominal aorta. We report a patient with impending rupture of a descending thoracic aorta aneurysm who underwent endovascular aortic repair using a transapical approach through the left ventricular apex.

\section{CLINICAL SUMMARY}

An 83-year-old man with history of systemic hypertension, dilated cardiomyopathy, chronic atrial fibrillation, diabetes mellitus, and chronic renal insufficiency was admitted to the emergency department of our hospital for

\footnotetext{
From the Heart Surgery Department, Parma University Hospital, Parma, Italy. Disclosures: Authors have nothing to disclose with regard to commercial support. Received for publication July 14, 2012; revisions received Aug 7, 2012; accepted for publication Aug 17, 2012; available ahead of print Sept 10, 2012.

Address for reprints: Francesco Nicolini, MD, PhD, Heart Surgery Section, Parma University Hospital, Via A. Gramsci 14, 43100 Parma, Italy (E-mail: francesco. nicolini@unipr.it).

J Thorac Cardiovasc Surg 2012;144:e123-5

$0022-5223 / \$ 36.00$

Copyright (C) 2012 by The American Association for Thoracic Surgery

http://dx.doi.org/10.1016/j.jtcvs.2012.08.039
}

cough with hemoptysis. A thoracoabdominal computed tomographic scan showed a multiple saccular pseudoaneurysm $(38 \times 57 \times 40 \mathrm{~mm})$ located on the left superolateral margin of the aortic wall, just beyond the origin of the left subclavian artery, with parietal thrombosis and perivascular hematoma (Figure 1, A). The lesion was complicated by the presence of 2 penetrating ulcers with bulging of the aortic wall. In this location, the inner layer of the aorta seemed to be very thin and partially interrupted. Angiography performed in the operating room confirmed the diagnosis. Unfortunately, emergency standard retrograde delivery of a thoracic stent graft was not feasible because of severe occlusive disease of the iliofemoral vessels (Figure 1,B). Moreover, the presence of a significant right subclavian artery tortuosity was judged to be an important and additional concern. Thus, considering the concomitant systemic comorbidities of the patient, and our experience with transapical aortic valve replacement, we decided that this minimally invasive approach would be the best option to deploy the endovascular aortic stent.

The patient was placed under general anesthesia and intubated with a single-lumen endotracheal tube. Imaging was provided by an angiographic C-arm system (Philips Veradius R1; Philips Healthcare, Best, The Netherlands). A left minithoracotomy incision was made in the fifth 